\title{
A new paradigm for clinical trials in antibiotherapy?
}

\author{
Kevin B Laupland MD MS FRCPC ${ }^{1}$, David N Fisman MD MPH FRCPC ${ }^{2}$
}

$\mathrm{R}$ ecommending or actively prescribing antibiotics is a fundamental daily activity in the field of infectious diseases. Our primary objective is to offer the most effective agent to optimize patient outcomes. However, numerous issues, not limited to toxicity and tolerability, cost and risk for emergence of antimicrobial resistance, frequently influence our choice of therapeutic agents.

It is widely accepted that experimental clinical trials provide the strongest evidence to guide the choice of a given therapy. Numerous large trials (1-3) have been performed in some areas of infectious diseases, such as in viral hepatitis, HIV infection, vaccines and tuberculosis, that can help guide infectious disease specialists. However, it is ironic that for bacterial infections, which are undoubtedly the most common infectious diseases encountered by generalists and infectious diseases specialists, there is a paucity of evidence from well-performed randomized controlled trials.

We performed a brief exploratory review of the published literature to gain a sample of the contemporary body of evidence that may be used to help guide antibiotic prescribing practices. We searched PubMed using the terms "antibiotics" and "infections" and limited our review to human clinical trials published in the English language with links to full text articles. We arbitrarily chose to review 30 consecutive, recently published trials investigating systemic antibiotic therapies for bacterial infections (4-33). As shown in Table 1, many of the studies were relatively small, with a median sample size of 218 patients (interquartile range 109 to 434 patients); the trials did not identify a superior treatment strategy. Few studies focused on severe infections, and none included mortality as a primary outcome measure. Remarkably, eight of 30 trials investigated various different regimens for treating Helicobacter pylori infections (Table 1).

These trials represent only a small and, potentially biased, sample of current evidence. While they may be reflective, they are by no means proof of depth of the literature base. Nonetheless, it is our anecdotal experience clinically and from interhospital rounds, meetings and committees, that most decisions and recommendations for infectious diseases related to antibacterial therapies are based on laboratory, clinical experience and, perhaps most frequently, arbitrary personal preference.

Conduct of antibiotherapy trials has been challenged by a number of factors, the most important of which is the immense cost associated with the conduct of clinical trials. Public research funding bodies rarely support comparative antibiotic clinical trials, and there is understandably little interest from industry to fund the evaluation of older off-patent agents. Pharmaceutical industry-supported trials are typically designed to fulfill regulatory requirements for new agents. These studies, therefore, generally aim to demonstrate safety and noninferiority of the new agent compared with standard therapies. It is well recognized that once agents are approved and available for one indication, they are rapidly used by clinicians for a range of other infections in patients who were not included in the trials (34). However, frequently, we are left with ongoing questions regarding the optimal management of these untested indications.

As clinicians, we recognize that many agents, even if suboptimal, successfully treat mild to moderate infections. We are grateful to have even a relatively small amount of clinical trial literature to support our options. However, what we often really want to know, and are asked to provide expertise in consultation, is whether one agent will improve a patient's chance of survival over another. However, is it realistic for us to expect clinical trials to demonstrate superiority of one antibacterial agent over another? We can argue that for a serious life-threatening infection, a demonstrated absolute reduction (as low as $1 \%$ ) in the risk of death would provide support for use of one agent over another. A small benefit, such as the one previously described, has been used as justification for the use of certain agents in other disciplines (35). However, if a $1 \%$ mortality difference is chosen to be clinically significant $(\alpha=0.05$, two-tailed, $\beta=0.1)$, then at control group mortality rates of $10 \%, 25 \%$ and $50 \%$, approximately 40,000 , 80,000 and 100,000 patients would need to be enrolled, respectively!

Because of these challenges, we have often turned to observational studies to gain insight into optimal treatments. Increasingly large and complex databases have enabled the assessment of treatments and outcomes on a large scale $(36,37)$. These observational designs are particularly useful when mortality is the outcome because this may be reliably determined using vital statistics data. However, at the risk of oversimplification, the Achilles' heel of observational studies is that observed differences in treatment outcomes may be falsely attributed to an uneven distribution of confounding variables. Multivariable regression and other statistical methodologies (such as the use of instrumental variables) may permit adjustment for unmeasured confounders, and may be particularly attractive given the well-recognized regional variation in patterns of medical practice. These have been used to evaluate drivers of antimicrobial overuse (38) and the impact of antimicrobials on outcomes in chronic obstructive pulmonary disease exacerbations (37). However, to our knowledge, these methods have not yet been applied to the question of differential effectiveness of various antimicrobial classes, and ameliorate - rather than eliminate - issues related to residual confounding. It must be recognized that while analytic approaches may be used to account for known confounding effects, only randomization offers protection from confounding effects due to unknown variables.

On one hand, clinical trials are the 'gold standard' to demonstrate the efficacy of a treatment; however, to date, they have frequently suffered from small sample sizes and, due to cost limitations, they have rarely shown superiority of one strategy over another for important clinical outcomes. The inclusion of strict enrollment criteria has also limited the ability to generalize results to other infections or patient populations. Observational studies are efficient and are able to include large numbers and ranges of patient types; however, by design, they are not able to provide proof regarding superiority of a treatment over another because of the confounding risk. Is it possible for these approaches to be merged to better establish optimal treatment strategies for bacterial infections?

More than 10 years previously, Peto and Baigent (39) argued for more simplified trials involving a large number of patients. They proposed that such study protocols would be simple and flexible, with a minimum of trial-specific data collected, and argued that while such studies would lose fine detail and lack stringent control of cointerventions, these limitations would presumably be balanced by the vastly increased statistical power of such designs. It is our belief that such trials could be of value in the field of infectious diseases and that they would be greatly facilitated by the increasing availability and extent of data captured in routine clinical databases.

${ }^{1}$ Departments of Medicine, Critical Care Medicine, Pathology and Laboratory Medicine, Centre for Antimicrobial Resistance, University of Calgary, Calgary Laboratory Services, Calgary Health Region, Calgary, Alberta; ${ }^{2}$ Dalla Lana School of Public Health, Toronto, Ontario

Correspondence: Dr Kevin B Laupland, Peter Lougheed Centre, 3500-36th Street Northeast, Calgary, Alberta T1Y 6J4.

Telephone 403-943-5785, fax 403-291-1491, e-mail kevin.laupland@calgaryhealthregion.ca 
TABLE 1

Consecutive sample of contemporary randomized clinical trials of systemic antibiotics for treatment of bacterial infections

\begin{tabular}{|c|c|c|}
\hline $\begin{array}{l}\text { First author } \\
\text { (reference) }\end{array}$ & $\begin{array}{l}\text { Funding } \\
\text { source }\end{array}$ & Context \\
\hline Louie (4) & Industry & $\begin{array}{l}\text { Fidaxomicin versus vancomycin for Clostridium difficile } \\
\text { infection }\end{array}$ \\
\hline Zheng (5) & Not stated & $\begin{array}{l}\text { 7-day triple therapy versus } 10 \text {-day quadruple therapy for } \\
\text { Helicobacter pylori eradication in nonulcer dyspepsia }\end{array}$ \\
\hline Judlin (6) & Industry & $\begin{array}{l}\text { Moxifloxacin versus levofloxacin plus metronidazole for } \\
\text { uncomplicated pelvic inflammatory disease }\end{array}$ \\
\hline Jia (7) & Industry & $\begin{array}{l}\text { Biapenem versus imipenem/cilastatin for urinary and } \\
\text { respiratory tract infections }\end{array}$ \\
\hline Towfigh (8) & Industry & $\begin{array}{l}\text { Tigecycline versus ceftriaxone metronidazole for } \\
\text { complicated intra-abdominal infections }\end{array}$ \\
\hline Assem (9) & Independent & $\begin{array}{l}\text { Clarithromycin plus amoxicillin plus esomeprazole versus } \\
\text { levofloxacin plus amoxicillin plus esomeprazole versus } \\
\text { levofloxacin plus clarithromycin plus esomeprazole for } \\
\text { H pylori eradication }\end{array}$ \\
\hline Ito (10) & Not stated & $\begin{array}{l}\text { Tazobactam/piperacillin versus imipenem/cilastatin for } \\
\text { aspiration pneumonia }\end{array}$ \\
\hline Sun (11) & Government & $\begin{array}{l}7 \text { versus } 14 \text { days of a 4-drug therapy for } H \text { pylori-associated } \\
\text { dyspepsia }\end{array}$ \\
\hline Bleidorn (12) & Not stated & $\begin{array}{l}\text { Ibuprofen versus ciprofloxacin for uncomplicated urinary } \\
\text { tract infection symptoms }\end{array}$ \\
\hline $\begin{array}{l}\text { Mokabberi } \\
\text { (13) }\end{array}$ & Not stated & $\begin{array}{l}\text { Community-acquired pneumonia treated with levofloxacin } \\
\text { versus doxycycline }\end{array}$ \\
\hline $\begin{array}{l}\text { Oztoprak } \\
\text { (14) }\end{array}$ & Not stated & $\begin{array}{l}\text { Piperacillin/tazobactam versus carbapenem with or } \\
\text { without amikacin for febrile neutropenia }\end{array}$ \\
\hline Liou (15) & $\begin{array}{l}\text { Government } \\
\text { and industry }\end{array}$ & $\begin{array}{l}\text { Levofloxacin- versus clarithromycin-based triple therapy } \\
\text { for } H \text { pylori infection for first- and second-line therapy }\end{array}$ \\
\hline
\end{tabular}

Randomized

patients,

629 Clinical cure 88\% fidaxomicin Fidaxomicin noninferior versus $86 \%$ vancomycin

170 Eradication rates $64 \%$ versus 10 -day quadruple regimen $89 \%$ significantly higher eradication rate

$460 \quad$ Test of cure $78 \%$ versus

Moxifloxacin noninferior $82 \%$

216 Cure $68 \%$ versus $76 \%$

No significant differences

$473 \quad$ Clinical response $70 \%$ versus $74 \%$

450 Eradication rates of $91 \%$ versus $85 \%$ versus $79 \%$

Tigecycline noninferior

Clarithromycin plus amoxicillin plus levofloxacin inferior
Minakari (16) Independent Azithromycin plus ofloxacin plus bismuth plus omeprazole versus amoxicillin plus clarithromycin plus bismuth plus omeprazole for second-line therapy of $H$ pylori infection

\footnotetext{
Hook (17) Government Azithromycin versus penicillin for early syphilis infection and industry

Schmitz (18) Government Cotrimoxazole versus placebo after incision and drainage for skin abscess

Itani (19) Industry Linezolid versus vancomycin for complicated skin and soft tissue infections due to methicillin-resistant Staphylococcus aureus (MRSA)

Gomez (20) Not stated Low-dose cefepime plus amikacin versus piperacillin/ tazobactam plus amikacin for febrile neutropenia

Paoluzi (21) Not stated 10- versus 8-day sequential therapy versus 7-day standard therapy for $H$ pylori eradication

Luaces-Rey Not stated Short versus long amoxicillin prophylaxis after third molar (22) removal

Carter (23) Not stated Combination antibiotics versus placebo for chlamydia-associated arthritis

Jung (24) Government Rifampin plus vancomycin versus vancomycin for MRSA pneumonia

Hung (25) Independent Clarithromycin- versus levofloxacin-based triple therapy for $\mathrm{H}$ pylori eradication

Feurle (26) Government Ceftriaxone versus meropenem, each followed by cotrimoxazole for Whipple's disease

Heystek (27) Industry Moxifloxacin versus doxycyclin plus metronidazole plus ciprofloxacin for uncomplicated pelvic inflammatory disease

Agah (28) Not stated Quadruple regimens including azithromycin versus metronidazole for $H$ pylori eradication
}

160

80

66

Clinical cure rates $83 \%$ versus $82 \%$

Eradication rates 80\% versus $94 \%$

$58 \%$ versus $52 \%$ symptom free at 4 days

$93 \%$ versus $97 \%$ clinical cure

Treatment success 88\% versus $75 \%$

First-line cure rate $74 \%$ versus $84 \%$; second line $77 \%$ versus $60 \%$

Eradication rates $77 \%$ versus $65 \%$
No significant differences

14-day course significantly better

No difference in response rates

No significant differences

Not significantly different

Clarithromycin regimen superior for primary therapy and levofloxacin regimen for secondary therapy

Azithromycin plus ofloxacin plus bismuth plus omeprazole higher eradication rate

$517 \quad 78 \%$ versus $79 \%$ serological Equivalence cure rates

212 Treatment failure $17 \%$ versus No difference at day 7 $26 \%$ at day 7

$84 \%$ versus $80 \%$ clinical success at study end by per-protocol analysis

Success $59 \%$ versus $64 \%$

Linezolid noninferior

$86 \%$ versus $83 \%$ versus $66 \%$ $3 \%$ in each group

$63 \%$ versus $20 \%$ clinical response

Combination therapy more effective

$54 \%$ versus $31 \%$ clinical cure at day 14

No difference

$93 \%$ versus $85 \%$ eradication effective

Full response in both groups

mycin-based therapy more effective

434

97\% versus $98 \%$ clinical success

No difference

Moxifloxacin noninferior

$69 \%$ versus $68 \%$

No difference
Postoperative infection rates No differences 
TABLE 1 - CONTINUED

Consecutive sample of contemporary randomized clinical trials of systemic antibiotics for treatment of bacterial infections

\begin{tabular}{|c|c|c|c|c|c|}
\hline $\begin{array}{l}\text { First author } \\
\text { (reference) }\end{array}$ & $\begin{array}{l}\text { Funding } \\
\text { source }\end{array}$ & Context & $\begin{array}{c}\text { Randomized } \\
\text { patients, } \\
\mathbf{n}\end{array}$ & Primary outcome & Conclusion \\
\hline $\begin{array}{l}\text { Estebanez } \\
(29)\end{array}$ & Not stated & $\begin{array}{l}\text { Fosfomycin versus amoxicillin-clavulanate for bacteriuria } \\
\text { in pregnancy }\end{array}$ & 109 & $\begin{array}{l}\text { Microbiological cure } 83 \% \text { versus } \\
80 \%\end{array}$ & No difference \\
\hline $\begin{array}{l}\text { Vick-Fragoso } \\
\text { (30) }\end{array}$ & Industry & $\begin{array}{l}\text { Moxifloxacin versus amoxicillin-clavulanate for } \\
\text { complicated skin and soft tissue infections }\end{array}$ & 804 & $\begin{array}{l}81 \% \text { versus } 85 \% \text { clinical } \\
\text { success rate }\end{array}$ & Moxifloxacin noninferior \\
\hline $\begin{array}{l}\text { Riethmueller } \\
\text { (31) }\end{array}$ & Industry & $\begin{array}{l}\text { Continuous versus three times daily ceftazidime for cystic } \\
\text { fibrosis }\end{array}$ & 56 & $\begin{array}{l}\text { Decrease mean leukocyte } \\
\text { count similar in both groups }\end{array}$ & No difference \\
\hline $\begin{array}{l}\text { Tanaseanu } \\
\text { (32) }\end{array}$ & Industry & $\begin{array}{l}\text { Tigecycline versus levofloxacin for community-acquired } \\
\text { pneumonia }\end{array}$ & 434 & $89 \%$ versus $85 \%$ & Tigecycline noninferior \\
\hline $\begin{array}{l}\text { Solomkin } \\
\text { (33) }\end{array}$ & Industry & $\begin{array}{l}\text { Moxifloxacin versus ceftriaxone plus metronidazole for } \\
\text { intra-abdominal infections }\end{array}$ & 364 & $\begin{array}{l}87 \% \text { versus } 91 \% \text { clinical } \\
\text { response }\end{array}$ & Moxifloxacin noninferior \\
\hline
\end{tabular}

One could envision the potential future feasibility of large trials to answer common clinically important questions in antibiotherapy. Once a patient is identified with a target condition, either clinically (ie, cellulitis) or by some other measure, such as positive culture (ie, bacteremia), the key step would be for clinicians to identify that patient as a candidate for treatment with two available agents for which there may be clinical equipoise (ie, cefazolin or cloxacillin for cellulitis; vancomycin or linezolid for methicillin-resistant Staphylococcus aureus [bacteremia]), and then randomly allocate that patient to one of the treatments. If routine existing data sources could be used to follow patients and establish outcomes (ie, electronic records, hospital administrative data or vital statistics registries), then much of the work in conducting the trial would be completed once allocation was complete. This streamlined approach would facilitate the enrollment of vastly larger numbers of patients for the same human resource expenditure of a typical contemporary trial.

Such an approach would have a number of benefits and limitations. This 'new' trial model would not be applicable to the use of new or unlicensed agents because they would need the rigorous and specific assessment of safety, which is only afforded by a traditional trial. As a result, the importance of and funding for these trials would need to be recognized and provided by public sources because industry would have little vested interest. The traditional trial is also preferred to assess efficacy, in which treatment may only be expected to have a benefit in a very specific or individualized target group. On the other hand, because enrollment criteria and management of patients are less strict and more similar to everyday practice, the new approach would be expected to be a measure of the effectiveness of a therapy. Perhaps the biggest challenge for this new approach would be the recognition that clinical research would have to be closely integrated with day-today clinical practice on a large scale. This would require the buy in of physicians and other health care workers, researchers, information technology experts, funding agencies and, most importantly, patients. Existing structures and relationships among infectious disease clinicians within Canada (eg, those created by the Association of Medical Microbiology and Infectious Disease Canada) could lend themselves to the creation of such large, simplified trial networks in the presence of energetic leadership and adequate funding.

\section{REFERENCES}

1. Sax PE, Tierney C, Collier AC, et al. Abacavir-lamivudine versus tenofovir-emtricitabine for initial HIV-1 therapy. N Engl J Med 2009;361:2230-40.

2. Benator D, Bhattacharya M, Bozeman L, et al. Rifapentine and isoniazid once a week versus rifampicin and isoniazid twice a week for treatment of drug-susceptible pulmonary tuberculosis in HIV-negative patients: A randomised clinical trial. Lancet 2002;360:528-34.

3. Medeiros LR, Rosa DD, da Rosa MI, Bozzetti MC, Zanini RR. Efficacy of human papillomavirus vaccines: A systematic quantitative review. Int J Gynecol Cancer 2009;19:1166-76.

4. Louie TJ, Miller MA, Mullane KM, et al. Fidaxomicin versus vancomycin for Clostridium difficile infection. N Engl J Med 2011;364:422-31.

5. Zheng Q, Chen WJ, Lu H, Sun QJ, Xiao SD. Comparison of the efficacy of triple versus quadruple therapy on the eradication of Helicobacter pylori and antibiotic resistance. J Dig Dis 2010;11:313-8.

6. Judlin P, Liao Q, Liu Z, Reimnitz P, Hampel B, Arvis P. Efficacy and safety of moxifloxacin in uncomplicated pelvic inflammatory disease: The MONALISA study. BJOG 2010;117:1475-84.

7. Jia B, Lu P, Huang W, et al. A multicenter, randomized controlled clinical study on biapenem and imipenem/cilastatin injection in the treatment of respiratory and urinary tract infections. Chemotherapy 2010;56:285-90.

8. Towfigh S, Pasternak J, Poirier A, Leister H, Babinchak T. A multicentre, open-label, randomized comparative study of tigecycline versus ceftriaxone sodium plus metronidazole for the treatment of hospitalized subjects with complicated intra-abdominal infections. Clin Microbiol Infect 2010;16:1274-81.

9. Assem M, El Azab G, Rasheed MA, Abdelfatah M, Shastery M. Efficacy and safety of levofloxacin, clarithromycin and esomeprazol as first line triple therapy for Helicobacter pylori eradication in Middle East. Prospective, randomized, blind, comparative, multicenter study. Eur J Intern Med 2010;21:310-4.

10. Ito I, Kadowaki S, Tanabe N, et al. Tazobactam/piperacillin for moderate-to-severe pneumonia in patients with risk for aspiration: Comparison with imipenem/cilastatin. Pulm Pharmacol Ther 2010;23:403-10.

11. Sun Q, Liang X, Zheng Q, et al. High efficacy of 14-day triple therapy-based, bismuth-containing quadruple therapy for initial Helicobacter pylori eradication. Helicobacter 2010;15:233-8.

12. Bleidorn J, Gagyor I, Kochen MM, Wegscheider K, Hummers-Pradier E: Symptomatic treatment (ibuprofen) or antibiotics (ciprofloxacin) for uncomplicated urinary tract infection? Results of a randomized controlled pilot trial. BMC Med 2010;8:30.

13. Mokabberi R, Haftbaradaran A, Ravakhah K. Doxycycline vs. levofloxacin in the treatment of community-acquired pneumonia. J Clin Pharm Ther 2010;35:195-200.

14. Oztoprak N, Piskin N, Aydemir H, et al. Piperacillin-tazobactam versus carbapenem therapy with and without amikacin as empirical treatment of febrile neutropenia in cancer patients: Results of an open randomized trial at a university hospital. Jpn J Clin Oncol 2010;40:761-7

15. Liou JM, Lin JT, Chang CY, et al. Levofloxacin-based and clarithromycin-based triple therapies as first-line and second-line treatments for Helicobacter pylori infection: A randomised comparative trial with crossover design. Gut 2010;59:572-8

16. Minakari M, Davarpanah Jazi AH, Shavakhi A, Moghareabed N, Fatahi F. A randomized controlled trial: Efficacy and safety of 
azithromycin, ofloxacin, bismuth, and omeprazole compared with amoxicillin, clarithromycin, bismuth, and omeprazole as second-line therapy in patients with Helicobacter pylori infection.

Helicobacter 2010;15:154-9.

17. Hook EW III, Behets F, Van Damme K, et al. A phase III equivalence trial of azithromycin versus benzathine penicillin for treatment of early syphilis. J Infect Dis 2010;201:1729-35.

18. Schmitz GR, Bruner D, Pitotti R, et al. Randomized controlled trial of trimethoprim-sulfamethoxazole for uncomplicated skin abscesses in patients at risk for community-associated methicillin-resistant Staphylococcus aureus infection. Ann Emerg Med 2010;56:283-7.

19. Itani KM, Dryden MS, Bhattacharyya H, Kunkel MJ, Baruch AM, Weigelt JA. Efficacy and safety of linezolid versus vancomycin for the treatment of complicated skin and soft-tissue infections proven to be caused by methicillin-resistant Staphylococcus aureus. Am J Surg 2010;199:804-16.

20. Gomez L, Estrada C, Gomez I, et al. Low-dose beta-lactam plus amikacin in febrile neutropenia: Cefepime vs. piperacillin/ tazobactam, a randomized trial. Eur J Clin Microbiol Infect Dis 2010;29:417-27.

21. Paoluzi OA, Visconti E, Andrei F, et al. Ten and eight-day sequential therapy in comparison to standard triple therapy for eradicating Helicobacter pylori infection: A randomized controlled study on efficacy and tolerability. J Clin Gastroenterol 2010;44:261-6.

22. Luaces-Rey R, Arenaz-Bua J, Lopez-Cedrun-Cembranos JL, Martinez-Roca C, Pertega-Diaz S, Sironvalle-Soliva S. Efficacy and safety comparison of two amoxicillin administration schedules after third molar removal. A randomized, double-blind and controlled clinical trial. Med Oral Patol Oral Cir Bucal 2010;15:e633-8.

23. Carter JD, Espinoza LR, Inman RD, et al. Combination antibiotics as a treatment for chronic chlamydia-induced reactive arthritis: A double-blind, placebo-controlled, prospective trial. Arthritis Rheum 2010;62:1298-307.

24. Jung YJ, Koh Y, Hong SB, et al. Effect of vancomycin plus rifampicin in the treatment of nosocomial methicillin-resistant Staphylococcus aureus pneumonia. Crit Care Med 2010;38:175-80.

25. Hung IF, Chan P, Leung S, et al. Clarithromycin-amoxycillincontaining triple therapy: A valid empirical first-line treatment for Helicobacter pylori eradication in Hong Kong? Helicobacter 2009;14:505-11.

26. Feurle GE, Junga NS, Marth T. Efficacy of ceftriaxone or meropenem as initial therapies in Whipple's disease. Gastroenterology 2010;138:478-86; quiz 411-72.

27. Heystek M, Ross JD. A randomized double-blind comparison of moxifloxacin and doxycycline/metronidazole/ciprofloxacin in the treatment of acute, uncomplicated pelvic inflammatory disease. Int J STD AIDS 2009;20:690-5.

28. Agah S, Shazad B, Abbaszadeh B. Comparison of azithromycin and metronidazole in a quadruple-therapy regimen for Helicobacter pylori eradication in dyspepsia. Saudi J Gastroenterol 2009;15:225-8.

29. Estebanez A, Pascual R, Gil V, Ortiz F, Santibanez M, Perez Barba C. Fosfomycin in a single dose versus a 7-day course of amoxicillin-clavulanate for the treatment of asymptomatic bacteriuria during pregnancy. Eur J Clin Microbiol Infect Dis 2009;28:1457-64.

30. Vick-Fragoso R, Hernandez-Oliva G, Cruz-Alcazar J, et al. Efficacy and safety of sequential intravenous/oral moxifloxacin vs intravenous/oral amoxicillin/clavulanate for complicated skin and skin structure infections. Infection 2009;37:407-17.

31. Riethmueller J, Junge S, Schroeter TW, et al. Continuous vs thrice-daily ceftazidime for elective intravenous antipseudomonal therapy in cystic fibrosis. Infection 2009;37:418-23.

32. Tanaseanu C, Milutinovic S, Calistru PI, et al. Efficacy and safety of tigecycline versus levofloxacin for community-acquired pneumonia. BMC Pulm Med 2009;9:44.

33. Solomkin J, Zhao YP, Ma EL, Chen MJ, Hampel B. Moxifloxacin is non-inferior to combination therapy with ceftriaxone plus metronidazole in patients with community-origin complicated intra-abdominal infections. Int J Antimicrob Agents 2009;34:439-45.

34. Keynan Y, Rubinstein E. Are drug clinical trials broadly applicable? The case of staphylococcal bacteraemia. Int J Antimicrob Agents 2009;34(Suppl 4):S35-37.

35. An international randomized trial comparing four thrombolytic strategies for acute myocardial infarction. The GUSTO investigators. N Engl J Med 1993;329:673-82.

36. Thomsen RW, Hundborg HH, Johnsen SP, et al. Statin use and mortality within 180 days after bacteremia: A population-based cohort study. Crit Care Med 2006;34:1080-6.

37. Rothberg MB, Pekow PS, Lahti M, Brody O, Skiest DJ, Lindenauer PK. Antibiotic therapy and treatment failure in patients hospitalized for acute exacerbations of chronic obstructive pulmonary disease. JAMA 2010;303:2035-42.

38. Filippini M, Masiero G, Moschetti K. Socioeconomic determinants of regional differences in outpatient antibiotic consumption: Evidence from Switzerland. Health Policy 2006;78:77-92.

39. Peto R, Baigent C. Trials: The next 50 years. Large scale randomised evidence of moderate benefits. BMJ 1998;317:1170-1. 


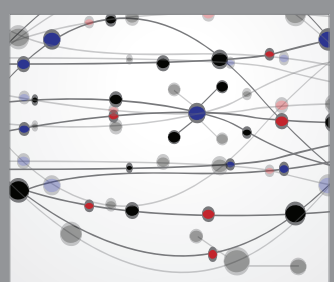

The Scientific World Journal
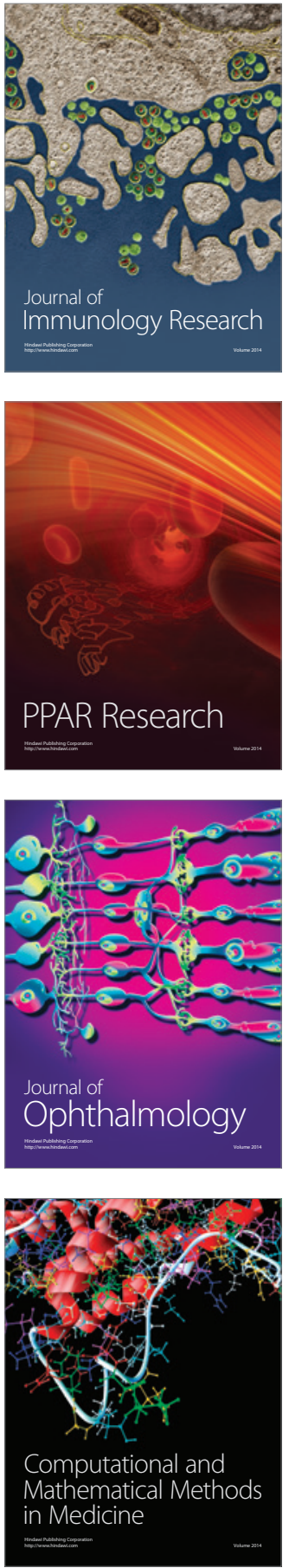

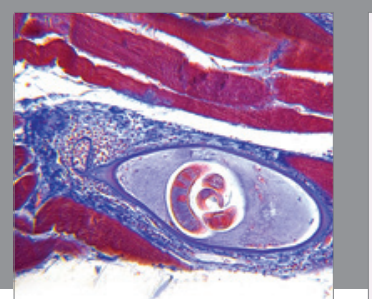

Gastroenterology Research and Practice

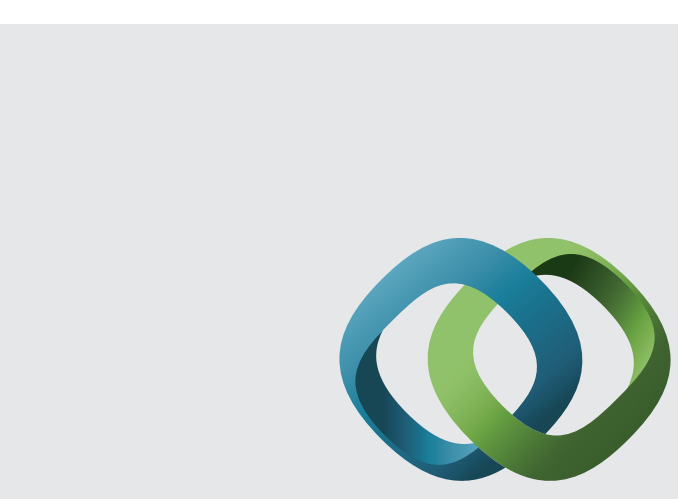

\section{Hindawi}

Submit your manuscripts at

http://www.hindawi.com
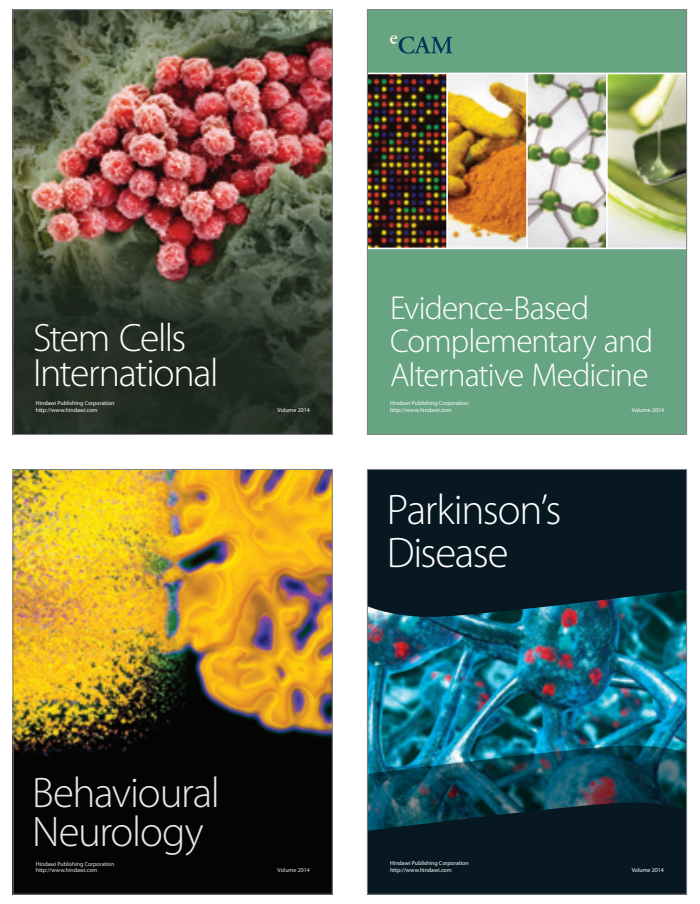
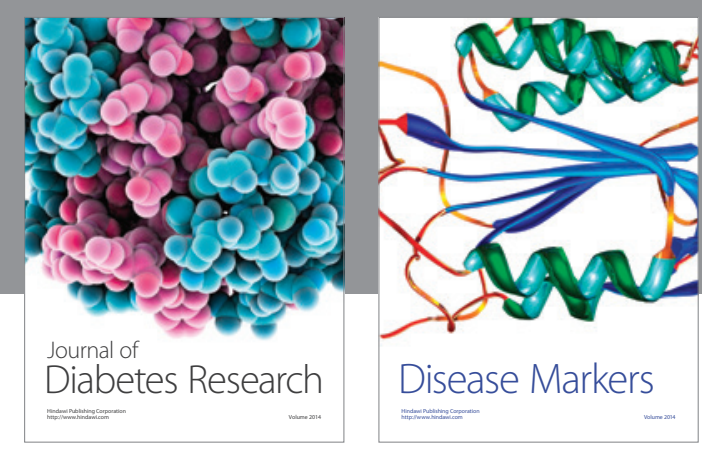

Disease Markers
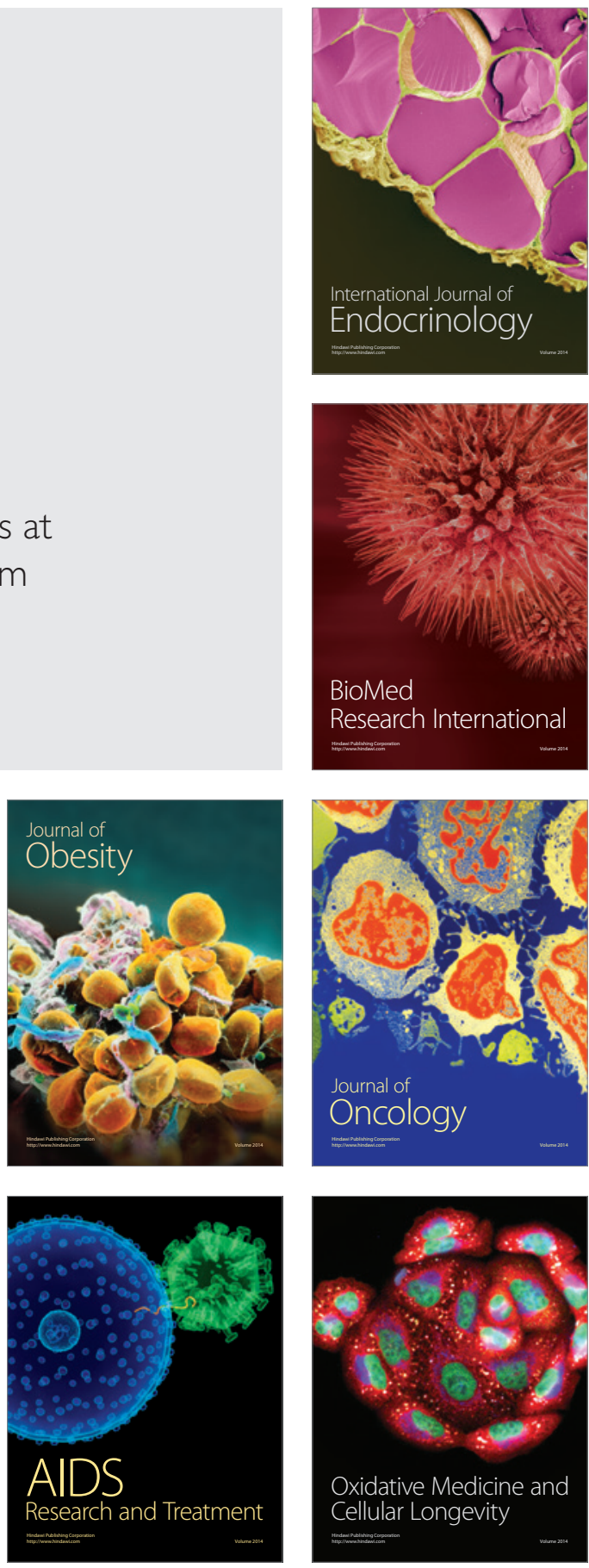